\title{
Neurosteroids in Adult Hippocampus of Male and Female Rodents: Biosynthesis and Actions of Sex Steroids
}

\author{
Yasushi Hojo ${ }^{1 *}$ and Suguru Kawato $2,3,4$ \\ 'Department of Biochemistry, Faculty of Medicine, Saitama Medical University, Moroyama, Saitama, Japan, \\ ${ }^{2}$ Department of Biophysics and Life Sciences, Graduate School of Arts and Sciences, The University of Tokyo, Tokyo, Japan, \\ ${ }^{3}$ Department of Urology, Graduate School of Medicine, Juntendo University, Tokyo, Japan, ${ }^{4}$ Department of Cognitive \\ Neuroscience, Faculty of Pharma-Science, Teikyo University, Tokyo, Japan
}

\section{OPEN ACCESS}

Edited by:

Takayoshi Ubuka, Monash University Malaysia, Malaysia

Reviewed by: Giuseppe Talani, Consiglio Nazionale Delle Ricerche (CNR), Italy Giuseppe Biagini, University of Modena and Reggio Emilia, Italy

*Correspondence: Yasushi Hojo yhojo@saitama-med.ac.jp

Specialty section: This article was submitted to Neuroendocrine Science, a section of the journal Frontiers in Endocrinology

Received: 02 February 2018 Accepted: 04 April 2018

Published: 23 April 2018

Citation:

Hojo Y and Kawato S (2018) Neurosteroids in Adult Hippocampus of Male and Female

Rodents: Biosynthesis and

Actions of Sex Steroids.

Front. Endocrinol. 9:183. doi: 10.3389/fendo.2018.00183
The brain is not only the target of steroid hormones but also is able to locally synthesize steroids de novo. Evidence of the local production of steroids in the brain has been accumulating in various vertebrates, including teleost fish, amphibia, birds, rodents, non-human primates, and humans. In this review, we mainly focus on the local production of sex steroids in the hippocampal neurons of adult rodents (rats and mice), a center for learning and memory. From the data of the hippocampus of adult male rats, hippocampal principal neurons [pyramidal cells in CA1-CA3 and granule cells in dentate gyrus (DG)] have a complete system for biosynthesis of sex steroids. Liquid chromatography with tandem-mass-spectrometry (LC-MS/MS) enabled us to accurately determine the levels of hippocampal sex steroids including $17 \beta$-estradiol (17 $\beta$-E2), testosterone (T), and dihydrotestosterone (DHT), which are much higher than those in blood. Next, we review the steroid synthesis in the hippocampus of female rats, since previous knowledge had been biased toward the data from males. Recently, we clarified that the levels of hippocampal steroids fluctuate in adult female rats across the estrous cycle. Accurate determination of hippocampal steroids at each stage of the estrous cycle is of importance for providing the account for the fluctuation of female hippocampal functions, including spine density, long-term potentiation (LTP) and long-term depression (LTD), and learning and memory. These functional fluctuations in female had been attributed to the level of circulation-derived steroids. LC-MS/MS analysis revealed that the dendritic spine density in CA1 of adult female hippocampus correlates with the levels of hippocampal progesterone and $17 \beta$-E2. Finally, we introduce the direct evidence of the role of hippocampus-synthesized steroids in hippocampal function including neurogenesis, LTP, and memory consolidation. Mild exercise (2 week of treadmill running) elevated synthesis of $\mathrm{DHT}$ in the hippocampus, but not in the testis, of male rats, resulting in enhancement of neurogenesis in DG. Concerning synaptic plasticity, hippocampus-synthesized E2 is required for LTP induction, whereas hippocampus-synthesized DHT is required for LTD induction. Furthermore, hippocampus-synthesized E2 is involved in memory consolidation tested by object recognition and object placement tasks, both of which are hippocampus-dependent.

Keywords: hippocampus, neurosteroids, estradiol, testosterone, dihydrotestosterone, estrous cycle, synaptic plasticity, neurogenesis 


\section{INTRODUCTION}

Extensive evidence has been accumulated that the systems of local steroid synthesis exist in the organs other than gonads and adrenal since 1980s $(1,2)$. Local production of steroids in the brain has been investigated in various vertebrates, including teleost fish $(3,4)$, amphibia $(5-7)$, birds $(8,9)$, rodents $(10-14)$, non-human primates, and humans (15-17).

For clinical purposes, the importance of neurosteroids is increasing. Because of the limitation to invade human brain tissues, quantitative determination of steroids in cerebrospinal fluid (CSF) has been applied to detect the alteration of the allopregnanolone (Allo) level under physiological/pathological conditions, including epilepsy $(18,19)$, and reproductive mood disorders $(20,21)$.

Sex steroids including $17 \beta$-estradiol (17 $\beta$-E2), testosterone (T), and dihydrotestosterone (DHT) are also synthesized in the brain. In this review, we mainly focus on the local production of sex steroids, particularly, E2, T, and DHT in the hippocampal neurons of adult rodents (rats and mice).

In addition to the genomic effects, sex steroids modulate neural functions in a rapid/non-genomic manner [reviewed in Ref. (22)]. Using the hippocampal slices of rodents, rapid effects of sex steroids have been extensively investigated. E2 modulates long-term potentiation (LTP) $(23,24)$ and long-term depression (LTD) $(25,26)$ in CA1 synapses. E2 induces LTP in CA1 under the weak theta burst stimulation (weak-TBS), which is not strong enough to induce LTP alone (27). Exogenous application of E2, T, and DHT to rat hippocampal slices, rapidly increases dendritic spines in CA1 pyramidal cells $(27,28)$.

Using exogenous application of steroids, these investigations demonstrated that rapid effects of sex steroids are mediated through estrogen receptors (ER $\alpha$ and ER $\beta$ ) or androgen receptors (AR), located at the pre/post synapses $(25,28-30)$, followed by the activation of kinases which phosphorylate the molecules essential for synaptic plasticity. Upon LTP-induction, E2 drives src tyrosine kinase and the extracellular signal-related protein kinase/MAPK (Erk MAPK), resulting in phosphorylation of NMDA receptor (23). In case of E2-induced LTP by weak-TBS, Erk MAPK, PKA, PKC, PI3K, and CaMkII phosphorylate NR2B subunit (27). In addition to postsynaptic modulation, E2 also activates ERs in presynapses, resulting in potentiation of glutamate release (31) or disinhibition of GABAergic axon terminal (32). Concerning spinogenesis, E2, T, or DHT drives Erk MAPK, p38 MAPK, PKA, PKC, PI3K, and LIMK $(27,28)$, which may phosphorylate cortactin $(33,34)$ and cofilin $(35,36)$, leading to actin polymerization and spinogenesis.

Do the effects of hippocampus-synthesized E2, T and DHT share the common mechanism described above? It is difficult, however, to directly demonstrate the roles of hippocampussynthesized E2, T, and DHT, because of the supply of E2, T, and DHT from testis or ovary. It is necessary to perform the experiment under the depletion of circulation-derived E2, T, and DHT, although the possibility is not excluded that peripherally produced precursors (e.g., pregnenolone and progesterone) convert into E2, T, or DHT in the hippocampus (Figure 1A). Several investigations are introduced in the Section "Physiological Roles of Hippocampus-Synthesized Steroids."

\section{STEROID BIOSYNTHESIS IN THE HIPPOCAMPUS}

\section{Steroid Biosynthesis in the Hippocampus of Adult Male Rodents}

Until about 15 years ago, it had not been elucidated whether adult hippocampal neurons have a complete system for synthesis of sex hormones (from cholesterol to androgens or estrogens) since $\mathrm{P} 450(17 \alpha)$, which is required for synthesis of dehydroepiandrosterone (DHEA) from pregnenolone (PREG), had been thought to be absent in the brain of mammals. Any effort to demonstrate the existence of $\mathrm{P} 450(17 \alpha)$ or its enzymatic activity had been unsuccessful (38-41) despite the presence of DHEA in the rodent brain even after castration $(1,2)$.

By using the hippocampus of adult male rats, the localization of $\mathrm{P} 450(17 \alpha)$ in the principal neurons [pyramidal cells in CA1-CA3 and granule cells in dentate gyrus (DG)] was demonstrated $(42,43)$. Immunohistochemistry and in situ hybridization studies revealed that StAR and other enzymes,

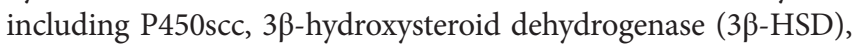
$17 \beta$-HSD, $5 \alpha$-reductase (types 1 and 2), and P450arom, are also localized in the hippocampal principal neurons of adult male rats and mice (37, 42-48). Studies with radioactive steroids directly demonstrated synthesis of PREG, DHEA, T, DHT, and E2 in slices or cultured hippocampal neurons from adult male rats in early 2000s $(42,43,47,49)$. These results suggest that complete systems for steroidogenesis exist in the hippocampal neurons of adult male rodents.

Interestingly, an electron microscopic (EM) analysis revealed synaptic localization of steroidogenic enzymes including P450 $(17 \alpha)$, P450arom, and $3 \beta$-HSD in the hippocampus of adult male rats $(42,50)$, implying the synaptic synthesis of sex steroids. EM and Western immunoblot analysis revealed localization of steroid receptors including $\mathrm{ER} \alpha, \mathrm{ER} \beta, \mathrm{AR}$, and progesterone receptor (PR) in the hippocampal synapses of rodents $(25,28-30,51,52)$.

Although these results give information about the potential to synthesize steroids in the hippocampus, it remains unclear whether hippocampus-synthesized steroids are effective enough to modulate hippocampal functions. To answer this question, it is necessary to quantitatively determine the concentration of steroids in the hippocampus. From early 2000s, quantitative determination of steroids, such as PREG, DHEA, and T in brain with mass-spectrometry (MS) began to emerge (53-58). The presence of pregnenolone sulfate (PREGS) in the brain of mammals had been a matter of debate (59).

To detect small amounts of steroids in the brain, purification of samples and selection of appropriate derivatization reagents are indispensable. Extracts from brain tissue contain various kinds of impurities (lipids and other steroids) which mask derivatization and ionization of the steroid of interest, resulting in decrease of detection efficiency of MS. Purification of the extracts by hybridSPE cartridges before LC-ESI-MS/MS enabled the detection of PREGS in the rat hippocampus (60). Concerning the detection of sex steroids, we removed impurities from hippocampal extracts and separated into fractions containing an individual steroid, with C18 column and normal phase HPLC before derivatization. 


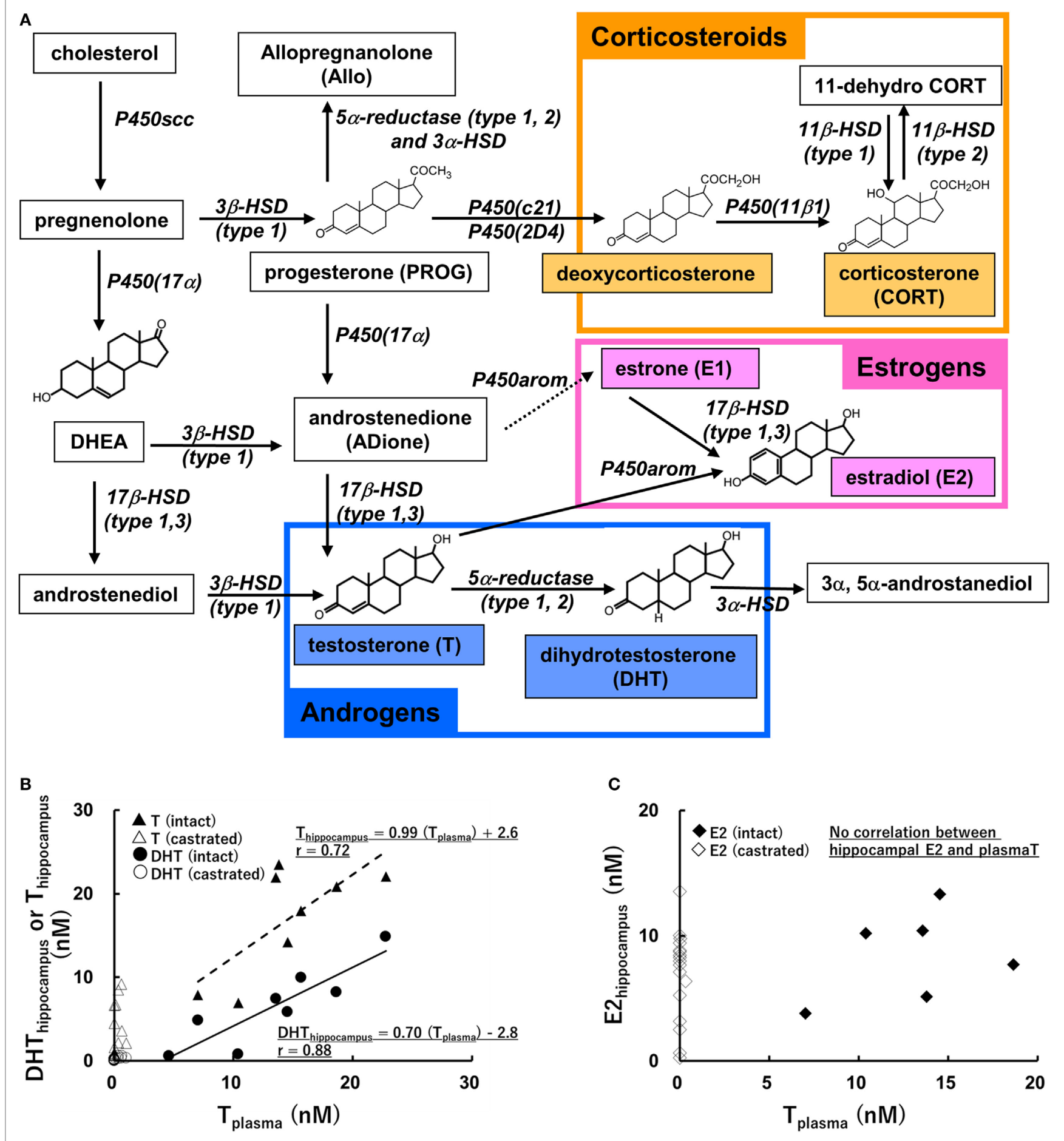

FIGURE 1 | (A) Biosynthetic pathway of steroids in rat hippocampus [modified from Ref. (11)]. Estrogens, androgens, and corticosteroids are represented with pink, blue, and orange boxes, respectively. (B,C) Relationship between the level of plasma T and those of hippocampal androgens [T and dihydrotestosteron (DHT)] (A), or that of hippocampal E2 (B). Vertical axis represents hippocampal steroids and horizontal axis represents plasma T, a precursor of DHT and E2. The regression lines and Pearson's "r" are indicated [modified from Ref. (37)].

Next, picolinoyl-derivatization was selected for steroids of interest (E2, T, DHT, and E1) to increase ionization efficiency $(61,62)$. Concerning E2, further derivatization with pentafluorobenzyl was performed to elevate volatility. In combination with these improvements, LC-MS/MS enabled us to quantitatively determine the concentration of E2, T, DHT, and E1 in the hippocampus, with high accuracy and reproducibility (37). Caruso and collaborators also determined the levels of steroids including E2, T, and DHT in 
rat hippocampus, with LC-MS/MS methods (63). These results support that the significant amount of sex steroids exists in the hippocampus.

Correlation between the level of hippocampal androgen ( T and DHT) and that of plasma T (Figure 1) was observed $(37,64)$. Hippocampal estrogen (E2), however, did not correlate with plasma $\mathrm{T}$ (Figure 1) $(37,64)$. Using male and female rats, Melcangi's laboratory extensively analyzed the correlation of steroid levels among plasma, CSF and various brain regions (63). According to this work, the levels of E2, T, and DHT in the hippocampus or CSF positively correlated with those in plasma, but no significant correlation of E2 level was observed between in the hippocampus and CSF (63).

\section{Synthesis and Fluctuation of Steroids in the Hippocampus of Adult Female Rodents}

Equally important is to clarify whether local steroid production occurs in female hippocampus, because sex hormones have a great impact on functions of female hippocampus [reviewed in Ref. (65)]. The knowledge of the hippocampus-synthesized steroids, however, had been biased toward the data from males (11-13) because of the estrous cycle in female animals. In case of rats and mice, estrous cycle comprises of four stages [proestrus: Pro, estrus: Est, diestrus1 (also called metestrus): D1, and diestrus2 (also called diestrus): D2], and each stage switches in 1 day in this order (66). Hippocampal functions such as spatial memory $(67-71), \operatorname{LTP}(72,73)$, and spine/ synapse density (74-78), fluctuate across the estrous cycle. To investigate hippocampal steroid synthesis in female rodents, therefore, fourfold as much data as those of male must be acquired.
LC-MS/MS analysis revealed the accurate concentrations of progesterone (PROG), androstenedione (ADione), T, E1, and E2 in the hippocampus of adult female rats at each stage of estrous cycle (Table 1) (79). The levels of plasma steroids exhibit typical estrous cycle dependent changes, in agreement with the previous study (80). The level of hippocampal E2 highly correlates with that of plasma E2, in agreement with other study (63). Concerning the correlation of PROG level between in hippocampus and in plasma, our data exhibit highly positive correlation, whereas others have no correlation (63). It may be due to the difference of samples used for calculation of correlations, rats of both sexes (male and diestrus female) in Caruso et al. (63) and only female (all four stages of the estrous cycle) in our study (79).

Surprisingly, mRNA levels of steroidogenic enzymes, including StAR, P450(17 $\alpha$ ), 17 $\beta$-HSD (types 1 and 3), $5 \alpha$-reductase (types 1 and 2), and $\mathrm{P} 450$ arom, did not fluctuate in the hippocampus across the estrous cycle $(79,81)$. Steroid receptors, including $E R \alpha, E R \beta$, $\mathrm{AR}$, and $\mathrm{PR}$, also kept their expression level constant. Moreover, no sex difference was observed concerning these enzymes in the hippocampus whose expression levels are approximately $1 / 300 \sim 1 / 1000$ of those in gonads or adrenals $(79,81,82)$.

Penetration of plasma E2 into the hippocampus, however, is not able to account for the level of hippocampal E2 because hippocampal E2 is much higher than that in plasma. There are two possibilities for explanation of hippocampal E2 fluctuation. The first is the fluctuation of blood PROG which is well known to fluctuate across the estrous cycle (80). This peripherally produced PROG may penetrate hippocampus and be converted into E2, resulting in E2 fluctuation. The other is the fluctuation of activity of kinases including MAPK, Akt, and LIMK, across the estrous cycle $(72,83,84)$. The activity of P450arom

TABLE 1 | Mass spectrometric analysis of the concentration of steroids in the hippocampus and plasma of adult rats.

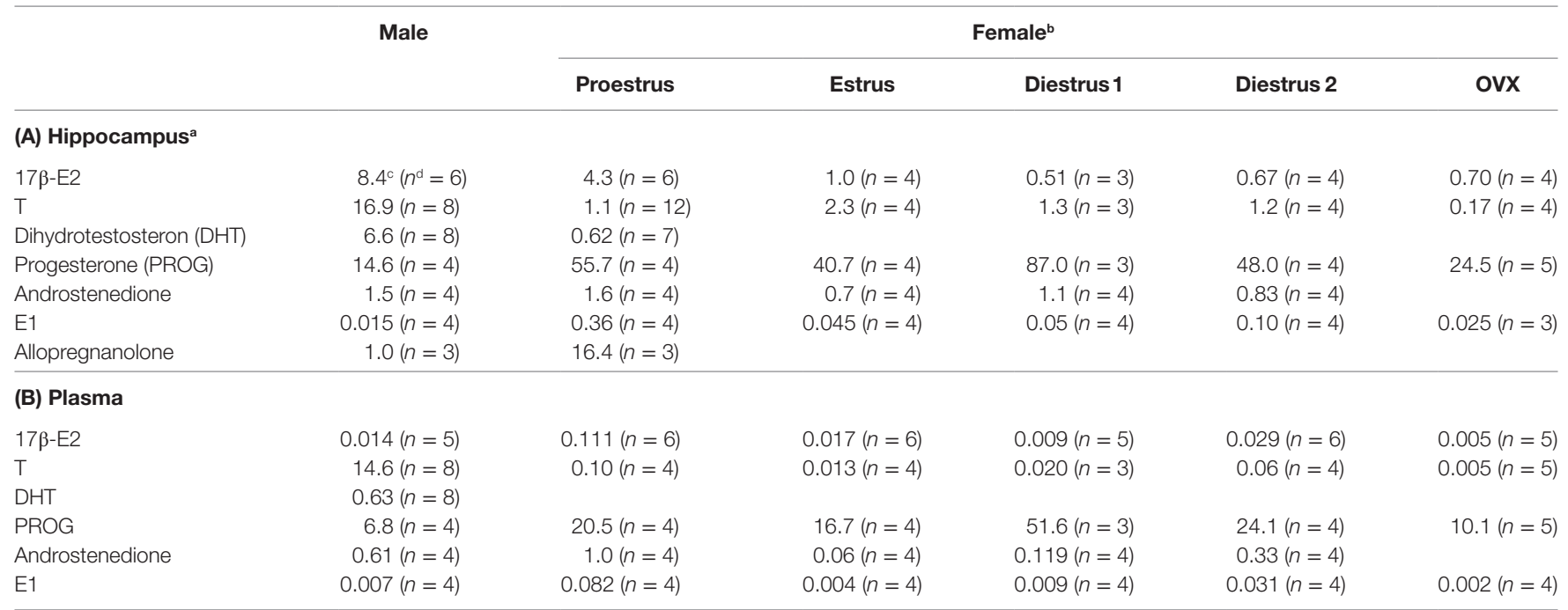

${ }^{a}$ Hippocampus was homogenized immediately after dissection from a decapitated head. This condition reflects the basal concentration of steroids in hippocampus.

${ }^{b}$ Female samples were prepared from rats at each stage of estrous cycle (Proestrus, Estrus, Diestrus1, and Diestrus 2) and ovariectomized (OVX) rats.

'Data are expressed as mean and are represented as nanomolar. Concentration in nanomolar is calculated using the average volume of $0.14 \mathrm{~mL}$ for one whole hippocampus that has $0.14 \pm 0.02 \mathrm{~g}$ wet weight $(n=86)$. We assume that tissue having $1 \mathrm{~g}$ of wet weight has an approximate volume of $1 \mathrm{~mL}$, since the major part of tissue consists of water whose $1 \mathrm{~mL}$ weight is $1 \mathrm{~g}(47)$.

${ }^{d}$ Number of animals.

Modified from Ref. $(37,79,81)$. 
(E2 synthase) changes upon phosphorylation (85). If the activity of kinases fluctuates, then following the fluctuation of P450arom activity may generate hippocampal E2 fluctuation, even if the mRNA levels of steroidogenic enzymes do not change across the estrous cycle.

Female hippocampus is equipped with systems for androgen synthesis from PROG [P450(17 $\alpha$ ), 17 $\beta$-HSD (types 1 and 3 ), $5 \alpha$-reductase (types 1 and 2)] and synthesizes DHT (Table 1) (81). In female hippocampus, a large amount of Allo is also synthesized from peripherally produced PROG because $5 \alpha$-reductase is responsible for Allo synthesis $(53,63,81)$.

\section{Regulation of Local Production of Steroids in Hippocampus}

A stimulation with NMDA for 30 min increases the levels of PREG and E2 in the hippocampal slices of adult male rats $(42,43,47)$, suggesting that neural activity-dependent $\mathrm{Ca}^{2+}$ influx drives local production of PREG and E2.

Reduction of P450arom activity by phosphorylation via kinases (PKA and PKC) is an important mechanism which regulates E2 synthesis. Balthazart et al. demonstrated that this phosphorylation occurred in the quail brain within $15 \mathrm{~min}$ (85-87). In the cultured hippocampal neurons of female rats, E2 application facilitated the phosphorylation of P450arom, suggesting negative feedback mechanism (88).

As slow/genomic modulators, cis-retinoic acid (89) and gonadotropin-releasing hormone (GnRH) (75) were examined using hippocampal slice culture from neonatal rats. Fortyeight-hour treatment with $1 \mu \mathrm{M}$ of 9-cis-retinoic acid increased the expression levels of $\mathrm{P} 450(17 \alpha)$ and $\mathrm{P} 450$ arom in the cultured hippocampal slices from male rats, via retinoid $\mathrm{X}$ receptor signaling (89). On the other hand, 8 days of treatment with GnRH enhanced local E2 production $(75,90)$. Hippocampal E2 synthesis was also increased by a stereotaxic injection of $\mathrm{GnRH}$ into the hippocampus of adult female rats (91).

Interestingly, behaviors, including social interaction $(92,93)$ and exercise (94), alter local production of steroids in the hippocampus. Social isolation (housing individually for 8 weeks) upregulated the mRNA levels of P450arom and StAR in the hippocampus of adult male rats, compared with pair housed rats (92), whereas environmental enrichment (housing in a group of nine in a large cage for 8 weeks) increased the mRNA levels of $5 \alpha$-reductase type 1 and $3 \alpha$-HSD (93).

\section{PHYSIOLOGICAL ROLES OF HIPPOCAMPUS-SYNTHESIZED STEROIDS}

\section{Hippocampus-Synthesized DHT Enhances Neurogenesis in DG}

Adult hippocampal neurogenesis occurs in DG throughout life in mammals (95). Sex steroids (96-99) and exercise $(100,101)$ enhance adult hippocampal neurogenesis of rodents, but the involvement of sex steroids in the exercise-induced neurogenesis, had been poorly understood.

Recently, Okamoto et al. revealed that mild exercise (30 $\mathrm{min} /$ day for 2 weeks) increased synthesis of hippocampal
DHT, resulting in the neurogenesis enhancement (94). Injection of flutamide, an AR antagonist, suppressed the exercise-induced increase in neurogenesis, suggesting the involvement of androgens. However, surprisingly, castration (depletion of androgen from blood circulation) did not suppress this effect, suggesting the involvement of hippocampus-synthesized androgens. Indeed, the increase in DHT and $5 \alpha$-reductase (DHT synthase) mRNA, were observed in the hippocampus of castrated rats after exercise (94). This study provides the direct evidence of the role of hippocampus-synthesized steroids in hippocampal functions.

\section{Modulation of LTP/LTD Induced by Hippocampus-Synthesized Steroids}

The physiological roles of hippocampus-synthesized sex steroids (E2 and DHT) in LTP/LTD were demonstrated in vitro studies using acute hippocampal slices and selective inhibitors of steroidogenic enzymes. A perfusion with letrozole, a selective inhibitor of P450arom, suppressed the magnitude of LTP in CA1-CA3 synapses of adult male rats (102), and in DG synapses of young (3- to 4-week old) male rats (103-104), within 10-20 min. ICI182,780, a selective antagonist of $E R \alpha / \beta$, mimicked this suppressive effect (102), suggesting that hippocampus-synthesized E2 is required for full induction of LTP via synaptic ER. Conversely, hippocampus-synthesized DHT is required for the induction of LTD, from the data showing that low frequency stimulation ( $1 \mathrm{~Hz}, 15 \mathrm{~min}$ )-induced LTD was suppressed in the presence of finasteride, an inhibitor of $5 \alpha$-reductase (105). In addition to sex steroids, the effect of hippocampus-synthesized PREG is reported, in which the application of aminoglutethimide, an inhibitor of $\mathrm{P} 450 \mathrm{scc}$, decreased the field excitatory postsynaptic potentials in granule cells in $20 \mathrm{~min}$ (103). Although the molecular mechanism underlying these effects remains unclear, a possible explanation may be provided by analogy from the data, showing that exogenous application of E2 rapidly (within $30 \mathrm{~min}$ ) enhanced LTP by driving kinase network (Erk MAPK, PKA, PKC, PI3K, and CaMKII) in a non-genomic manner $(27,106)$.

\section{Role of Hippocampus-Synthesized E2 in Hippocampus-Dependent Memory}

Recently, the role of hippocampus-synthesized E2 in hippocampus-dependent memory consolidation was provided using OVX mice (107). Immediate after the training, bilateral infusion of letrozole into the dorsal hippocampus blocked the transient elevation of hippocampal E2 (within $30 \mathrm{~min}$ ), and impaired object recognition and object placement memory consolidation (107). Under the same condition except for infusion of E2, this group previously demonstrated that E2 enhanced hippocampal memory consolidation via rapid activation of Erk MAPK and PI3K/Akt (108, 109), suggesting that learning experienceinduced E2 elevation in the hippocampus rapidly activates kinase cascades.

\section{CONCLUSION}

Hippocampus-synthesized steroids as well as circulationderived ones, are of importance for hippocampal functions. 
A possible molecular mechanism for rapid effect of hippocampussynthesized steroids may be kinase networks which modulate hippocampal functions, including spinogenesis $(106,110)$, LTP (27), learning, and memory $(108,109)$.

\section{REFERENCES}

1. Baulieu EE. Neurosteroids: of the nervous system, by the nervous system, for the nervous system. Recent Prog Horm Res (1997) 52:1-32.

2. Corpechot C, Robel P, Axelson M, Sjovall J, Baulieu EE. Characterization and measurement of dehydroepiandrosterone sulfate in rat brain. Proc Natl Acad Sci U S A (1981) 78:4704-7. doi:10.1073/pnas.78.8.4704

3. Diotel N, Do Rego JL, Anglade I, Vaillant C, Pellegrini E, Vaudry H, et al. The brain of teleost fish, a source, and a target of sexual steroids. Front Neurosci (2011) 5:137. doi:10.3389/fnins.2011.00137

4. Xing L, Goswami M, Trudeau VL. Radial glial cell: critical functions and new perspective as a steroid synthetic cell. Gen Comp Endocrinol (2014) 203:181-5. doi:10.1016/j.ygcen.2014.03.010

5. Tsutsui K, Haraguchi S, Fukada Y, Vaudry H. Brain and pineal 7alphahydroxypregnenolone stimulating locomotor activity: identification, mode of action and regulation of biosynthesis. Front Neuroendocrinol (2013) 34:179-89. doi:10.1016/j.yfrne.2013.05.002

6. Tsutsui K, Haraguchi S, Matsunaga M, Koyama T, Do Rego JL, Vaudry H. 7alpha-Hydroxypregnenolone, a new key regulator of amphibian locomotion: discovery, progress and prospect. Gen Comp Endocrinol (2012) 176:440-7. doi:10.1016/j.ygcen.2011.11.020

7. Vaudry H, Do Rego JL, Burel D, Luu-The V, Pelletier G, Vaudry D, et al. Neurosteroid biosynthesis in the brain of amphibians. Front Endocrinol (2011) 2:79. doi:10.3389/fendo.2011.00079

8. Heimovics SA, Prior NH, Ma C, Soma KK. Rapid effects of an aggressive interaction on dehydroepiandrosterone, testosterone and oestradiol levels in the male song sparrow brain: a seasonal comparison. J Neuroendocrinol (2016) 28:12345. doi:10.1111/jne.12345

9. Remage-Healey L, Saldanha CJ, Schlinger BA. Estradiol synthesis and action at the synapse: evidence for "synaptocrine" signaling. Front Endocrinol (2011) 2:28. doi:10.3389/fendo.2011.00028

10. Do Rego JL, Seong JY, Burel D, Leprince J, Luu-The V, Tsutsui K, et al. Neurosteroid biosynthesis: enzymatic pathways and neuroendocrine regulation by neurotransmitters and neuropeptides. Front Neuroendocrinol (2009) 30:259-301. doi:10.1016/j.yfrne.2009.05.006

11. Hojo Y, Higo S, Kawato S, Hatanaka Y, Ooishi Y, Muakami G, et al. Hippocampal synthesis of sex steroids and corticosteroids: essential for modulation of synaptic plasticity. Front Endocrinol (2011) 2:43. doi:10.3389/ fendo.2011.00043

12. Mukai H, Kimoto T, Hojo Y, Kawato S, Murakami G, Higo S, et al. Modulation of synaptic plasticity by brain estrogen in the hippocampus. Biochim Biophys Acta (2010) 1800:1030-44. doi:10.1016/j.bbagen.2009.11.002

13. Ooishi Y, Kawato S, Hojo Y, Hatanaka Y, Higo S, Murakami G, et al. Modulation of synaptic plasticity in the hippocampus by hippocampusderived estrogen and androgen. J Steroid Biochem Mol Biol (2012) 131:37-51. doi:10.1016/j.jsbmb.2011.10.004

14. Tsutsui K, Ukena K, Sakamoto H, Okuyama S, Haraguchi S. Biosynthesis, mode of action, and functional significance of neurosteroids in the purkinje cell. Front Endocrinol (2011) 2:61. doi:10.3389/fendo.2011.00061

15. Azcoitia I, Yague JG, Garcia-Segura LM. Estradiol synthesis within the human brain. Neuroscience (2011) 191:139-47. doi:10.1016/j.neuroscience. 2011.02.012

16. Melcangi RC, Panzica G, Garcia-Segura LM. Neuroactive steroids: focus on human brain. Neuroscience (2011) 191:1-5. doi:10.1016/j.neuroscience. 2011.06.024

17. Naftolin F, Horvath TL, Jakab RL, Leranth C, Harada N, Balthazart J. Aromatase immunoreactivity in axon terminals of the vertebrate brain. An immunocytochemical study on quail, rat, monkey and human tissues. Neuroendocrinology (1996) 63:149-55. doi:10.1159/000126951

18. Biagini G, Rustichelli C, Curia G, Vinet J, Lucchi C, Pugnaghi M, et al. Neurosteroids and epileptogenesis. J Neuroendocrinol (2013) 25:980-90. doi:10.1111/jne.12063

\section{AUTHOR CONTRIBUTIONS}

YH wrote the manuscript. SK brushed up the initial draft of the manuscript written by $\mathrm{YH}$.

19. Meletti S, Lucchi C, Monti G, Giovannini G, Bedin R, Trenti T, et al. Decreased allopregnanolone levels in cerebrospinal fluid obtained during status epilepticus. Epilepsia (2017) 58:e16-20. doi:10.1111/epi.13625

20. Martinez PE, Rubinow DR, Nieman LK, Koziol DE, Morrow AL, Schiller CE, et al. 5alpha-reductase inhibition prevents the luteal phase increase in plasma allopregnanolone levels and mitigates symptoms in women with premenstrual dysphoric disorder. Neuropsychopharmacology (2016) 41:1093-102. doi:10.1038/npp.2015.246

21. Schiller CE, Schmidt PJ, Rubinow DR. Allopregnanolone as a mediator of affective switching in reproductive mood disorders. Psychopharmacology (2014) 231:3557-67. doi:10.1007/s00213-014-3599-X

22. Murakami G, Hojo Y, Kato A, Komatsuzaki Y, Horie S, Soma M, et al. Rapid nongenomic modulation by neurosteroids of dendritic spines in the hippocampus: androgen, oestrogen and corticosteroid. J Neuroendocrinol (2018) 30:e12561. doi:10.1111/jne.12561

23. Bi R, Broutman G, Foy MR, Thompson RF, Baudry M. The tyrosine kinase and mitogen-activated protein kinase pathways mediate multiple effects of estrogen in hippocampus. Proc Natl Acad Sci U S A (2000) 97:3602-7. doi:10.1073/pnas.97.7.3602

24. Foy MR, Xu J, Xie X, Brinton RD, Thompson RF, Berger TW. 17beta-estradiol enhances NMDA receptor-mediated EPSPs and long-term potentiation. J Neurophysiol (1999) 81:925-9. doi:10.1152/jn.1999.81.2.925

25. Mukai H, Tsurugizawa T, Murakami G, Kominami S, Ishii H, Ogiue-Ikeda M, et al. Rapid modulation of long-term depression and spinogenesis via synaptic estrogen receptors in hippocampal principal neurons. J Neurochem (2007) 100:950-67. doi:10.1111/j.1471-4159.2006.04264.x

26. Vouimba RM, Foy MR, Foy JG, Thompson RF. 17beta-estradiol suppresses expression of long-term depression in aged rats. Brain Res Bull (2000) 53:783-7. doi:10.1016/S0361-9230(00)00377-4

27. Hasegawa Y, Hojo Y, Kojima H, Ikeda M, Hotta K, Sato R, et al. Estradiol rapidly modulates synaptic plasticity of hippocampal neurons: involvement of kinase networks. Brain Res (2015) 1621:147-61. doi:10.1016/j. brainres.2014.12.056

28. Hatanaka Y, Hojo Y, Mukai H, Murakami G, Komatsuzaki Y, Kim J, et al. Rapid increase of spines by dihydrotestosterone and testosterone in hippocampal neurons: dependence on synaptic androgen receptor and kinase networks. Brain Res (2015) 1621:121-32. doi:10.1016/j.brainres. 2014.12.011

29. Milner TA, Ayoola K, Drake CT, Herrick SP, Tabori NE, McEwen BS, et al. Ultrastructural localization of estrogen receptor beta immunoreactivity in the rat hippocampal formation. J Comp Neurol (2005) 491:81-95. doi:10.1002/cne.20724

30. Tabori NE, Stewart LS, Znamensky V, Romeo RD, Alves SE, McEwen BS, et al. Ultrastructural evidence that androgen receptors are located at extranuclear sites in the rat hippocampal formation. Neuroscience (2005) 130:151-63. doi:10.1016/j.neuroscience.2004.08.048

31. Smejkalova T, Woolley CS. Estradiol acutely potentiates hippocampal excitatory synaptic transmission through a presynaptic mechanism. J Neurosci (2010) 30:16137-48. doi:10.1523/JNEUROSCI.4161-10.2010

32. Tabatadze N, Huang G, May RM, Jain A, Woolley CS. Sex differences in molecular signaling at inhibitory synapses in the hippocampus. J Neurosci (2015) 35:11252-65. doi:10.1523/JNEUROSCI.1067-15.2015

33. Hering $H$, Sheng M. Activity-dependent redistribution and essential role of cortactin in dendritic spine morphogenesis. JNeurosci (2003) 23: 11759-69. doi:10.1523/JNEUROSCI.23-37-11759.2003

34. Iki J, Inoue A, Bito $\mathrm{H}$, Okabe $\mathrm{S}$. Bi-directional regulation of postsynaptic cortactin distribution by BDNF and NMDA receptor activity. Eur J Neurosci (2005) 22:2985-94. doi:10.1111/j.1460-9568.2005.04510.x

35. Aizawa H, Wakatsuki S, Ishii A, Moriyama K, Sasaki Y, Ohashi K, et al. Phosphorylation of cofilin by LIM-kinase is necessary for semaphorin 3Ainduced growth cone collapse. Nat Neurosci (2001) 4:367-73. doi:10.1038/ 86011 
36. Liston C, Cichon JM, Jeanneteau F, Jia Z, Chao MV, Gan WB. Circadian glucocorticoid oscillations promote learning-dependent synapse formation and maintenance. Nat Neurosci (2013) 16:698-705. doi:10.1038/nn.3387

37. Hojo Y, Higo S, Ishii H, Ooishi Y, Mukai H, Murakami G, et al. Comparison between hippocampus-synthesized and circulation-derived sex steroids in the hippocampus. Endocrinology (2009) 150:5106-12. doi:10.1210/en.2009-0305

38. Compagnone NA, Mellon SH. Neurosteroids: biosynthesis and function of these novel neuromodulators. Front Neuroendocrinol (2000) 21:1-56. doi:10.1006/frne.1999.0188

39. Le Goascogne C, Sananès N, Gouézou M, Takemori S, Kominami S, Baulieu EE, et al. Immunoreactive cytochrome P-450(17 alpha) in rat and guinea-pig gonads, adrenal glands and brain. J Reprod Fertil (1991) 93:609-22. doi:10.1530/jrf.0.0930609

40. Mellon SH, Deschepper CF. Neurosteroid biosynthesis: genes for adrenal steroidogenic enzymes are expressed in the brain. Brain Res (1993) 629: 283-92. doi:10.1016/0006-8993(93)91332-M

41. Robel P, Bourreau E, Corpéchot C, Dang DC, Halberg F, Clarke C, et al. Neuro-steroids: 3 beta-hydroxy-delta 5-derivatives in rat and monkey brain. J Steroid Biochem (1987) 27:649-55. doi:10.1016/0022-4731(87)90133-6

42. Hojo Y, Hattori TA, Enami T, Furukawa A, Suzuki K, Ishii HT, et al. Adult male rat hippocampus synthesizes estradiol from pregnenolone by cytochromes P45017alpha and P450 aromatase localized in neurons. Proc Natl Acad Sci U S A (2004) 101:865-70. doi:10.1073/pnas.2630225100

43. Kawato S, Hojo Y, Kimoto T. Histological and metabolism analysis of P450 expression in the brain. Methods Enzymol (2002) 357:241-9. doi:10.1016/ S0076-6879(02)57682-5

44. Agís-Balboa RC, Pinna G, Zhubi A, Maloku E, Veldic M, Costa E, et al. Characterization of brain neurons that express enzymes mediating neurosteroid biosynthesis. Proc Natl Acad Sci U S A (2006) 103:14602-7. doi:10.1073/pnas.0606544103

45. Castelli MP, Casti A, Casu A, Frau R, Bortolato M, Spiga S, et al. Regional distribution of 5alpha-reductase type 2 in the adult rat brain: an immunohistochemical analysis. Psychoneuroendocrinology (2013) 38:281-93. doi:10.1016/j.psyneuen.2012.06.008

46. Furukawa A, Miyatake A, Ohnishi T, Ichikawa Y. Steroidogenic acute regulatory protein (StAR) transcripts constitutively expressed in the adult rat central nervous system: colocalization of StAR, cytochrome P-450SCC (CYP XIA1), and 3beta-hydroxysteroid dehydrogenase in the rat brain. J Neurochem (1998) 71:2231-8. doi:10.1046/j.1471-4159.1998.71062231.x

47. Kimoto T, Tsurugizawa T, Ohta Y, Makino J, Tamura H, Hojo Y, et al. Neurosteroid synthesis by cytochrome p450-containing systems localized in the rat brain hippocampal neurons: N-methyl-D-aspartate and calciumdependent synthesis. Endocrinology (2001) 142:3578-89. doi:10.1210/endo. 142.8.8327

48. Wehrenberg U, Prange-Kiel J, Rune GM. Steroidogenic factor-1 expression in marmoset and rat hippocampus: co-localization with StAR and aromatase. J Neurochem (2001) 76:1879-86. doi:10.1046/j.1471-4159.2001.00207.x

49. Prange-Kiel J, Wehrenberg U, Jarry H, Rune GM. Para/autocrine regulation of estrogen receptors in hippocampal neurons. Hippocampus (2003) 13:226-34. doi:10.1002/hipo.10075

50. Higo S, Hojo Y, Ishii H, Komatsuzaki Y, Ooishi Y, Murakami G, et al. Endogenous synthesis of corticosteroids in the hippocampus. PLoS One (2011) 6:e21631. doi:10.1371/journal.pone.0021631

51. Mitterling KL, Spencer JL, Dziedzic N, Shenoy S, McCarthy K, Waters EM, et al. Cellular and subcellular localization of estrogen and progestin receptor immunoreactivities in the mouse hippocampus. J Comp Neurol (2010) 518:2729-43. doi:10.1002/cne.22361

52. Waters EM, Torres-Reveron A, McEwen BS, Milner TA. Ultrastructural localization of extranuclear progestin receptors in the rat hippocampal formation. J Comp Neurol (2008) 511:34-46. doi:10.1002/cne.21826

53. Caruso D, Pesaresi M, Maschi O, Giatti S, Garcia-Segura LM, Melcangi RC. Effect of short-and long-term gonadectomy on neuroactive steroid levels in the central and peripheral nervous system of male and female rats. J Neuroendocrinol (2010) 22:1137-47. doi:10.1111/j.1365-2826.2010.02064.x

54. Ebner MJ, Corol DI, Havlikova H, Honour JW, Fry JP. Identification of neuroactive steroids and their precursors and metabolites in adult male rat brain. Endocrinology (2006) 147:179-90. doi:10.1210/en.2005-1065

55. Higashi T, Ninomiya Y, Iwaki N, Yamauchi A, Takayama N, Shimada K. Studies on neurosteroids XVIII LC-MS analysis of changes in rat brain and serum testosterone levels induced by immobilization stress and ethanol administration. Steroids (2006) 71:609-17. doi:10.1016/j.steroids.2006.03.003

56. Liere P, Akwa Y, Weill-Engerer S, Eychenne B, Pianos A, Robel P, et al. Validation of an analytical procedure to measure trace amounts of neursteroids in brain tissue by gas chromatography-mass spectrometry. J Chromatogr B Biomed Sci Appl (2000) 739:301-12. doi:10.1016/S03784347(99)00563-0

57. Liu S, Sjovall J, Griffiths WJ. Neurosteroids in rat brain: extraction, isolation, and analysis by nanoscale liquid chromatography-electrospray mass spectrometry. Anal Chem (2003) 75:5835-46. doi:10.1021/ac0346297

58. Meffre D, Pianos A, Liere P, Eychenne B, Cambourg A, Schumacher M, et al. Steroid profiling in brain and plasma of male and pseudopregnant female rats after traumatic brain injury: analysis by gas chromatography/mass spectrometry. Endocrinology (2007) 148:2505-17. doi:10.1210/en.2006-1678

59. Schumacher M, Liere P, Akwa Y, Rajkowski K, Griffiths W, Bodin K, et al. Pregnenolone sulfate in the brain: a controversial neurosteroid. Neurochem Int (2008) 52:522-40. doi:10.1016/j.neuint.2007.08.022

60. Rustichelli C, Pinetti D, Lucchi C, Ravazzini F, Puia G. Simultaneous determination of pregnenolone sulphate, dehydroepiandrosterone and allopregnanolone in rat brain areas by liquid chromatography-electrospray tandem mass spectrometry. J Chromatogr B Analyt Technol Biomed Life Sci (2013) 930:62-9. doi:10.1016/j.jchromb.2013.04.035

61. Yamashita K, Kobayashi S, Tsukamoto S, Numazawa M. Synthesis of pyridinecarboxylate derivatives of hydroxysteroids for liquid chromatographyelectrospray ionization-mass spectrometry. Steroids (2007) 72:50-9. doi:10.1016/j.steroids.2006.10.005

62. Yamashita K, Okuyama M, Watanabe Y, Honma S, Kobayashi S, Numazawa M. Highly sensitive determination of estrone and estradiol in human serum by liquid chromatography-electrospray ionization tandem mass spectrometry. Steroids (2007) 72:819-27. doi:10.1016/j.steroids.2007.07.003

63. Caruso D, Pesaresi M, Abbiati F, Calabrese D, Giatti S, Garcia-Segura LM, et al. Comparison of plasma and cerebrospinal fluid levels of neuroactive steroids with their brain, spinal cord and peripheral nerve levels in male and female rats. Psychoneuroendocrinology (2013) 38:2278-90. doi:10.1016/j. psyneuen.2013.04.016

64. Barron AM, Hojo Y, Mukai H, Higo S, Ooishi Y, Hatanaka Y, et al. Regulation of synaptic plasticity by hippocampus synthesized estradiol. Horm Mol Biol Clin Investig (2011) 7:361-75. doi:10.1515/HMBCI.2011.118

65. Frick KM, Kim J, Tuscher JJ, Fortress AM. Sex steroid hormones matter for learning and memory: estrogenic regulation of hippocampal function in male and female rodents. Learn Mem (2015) 22:472-93. doi:10.1101/ $\operatorname{lm} .037267 .114$

66. Goldman JM, Murr AS, Cooper RL. The rodent estrous cycle: characterization of vaginal cytology and its utility in toxicological studies. Birth Defects Res B Dev Reprod Toxicol (2007) 80:84-97. doi:10.1002/bdrb.20106

67. Frick KM, Berger-Sweeney J. Spatial reference memory and neocortical neurochemistry vary with the estrous cycle in C57BL/6 mice. Behav Neurosci (2001) 115:229-37. doi:10.1037/0735-7044.115.1.229

68. Paris JJ, Frye CA. Estrous cycle, pregnancy, and parity enhance performance of rats in object recognition or object placement tasks. Reproduction (2008) 136:105-15. doi:10.1530/REP-07-0512

69. Pompili A, Tomaz C, Arnone B, Tavares MC, Gasbarri A. Working and reference memory across the estrous cycle of rat: a long-term study in gonadally intact females. Behav Brain Res (2010) 213:10-8. doi:10.1016/j. bbr.2010.04.018

70. Sutcliffe JS, Marshall KM, Neill JC. Influence of gender on working and spatial memory in the novel object recognition task in the rat. Behav Brain Res (2007) 177:117-25. doi:10.1016/j.bbr.2006.10.029

71. Warren SG, Juraska JM. Spatial and nonspatial learning across the rat estrous cycle. Behav Neurosci (1997) 111:259-66. doi:10.1037/0735-7044.111.2.259

72. Bi R, Foy MR, Vouimba RM, Thompson RF, Baudry M. Cyclic changes in estradiol regulate synaptic plasticity through the MAP kinase pathway. Proc Natl Acad Sci U S A (2001) 98:13391-5. doi:10.1073/pnas.241507698

73. Warren SG, Humphreys AG, Juraska JM, Greenough WT. LTP varies across the estrous cycle: enhanced synaptic plasticity in proestrus rats. Brain Res (1995) 703:26-30. doi:10.1016/0006-8993(95)01059-9

74. Gould E, Woolley CS, Frankfurt M, McEwen BS. Gonadal steroids regulate dendritic spine density in hippocampal pyramidal cells in adulthood. J Neurosci (1990) 10:1286-91. doi:10.1523/JNEUROSCI.10-04-01286.1990 
75. Prange-Kiel J, Jarry H, Schoen M, Kohlmann P, Lohse C, Zhou L, et al. Gonadotropin-releasing hormone regulates spine density via its regulatory role in hippocampal estrogen synthesis. J Cell Biol (2008) 180:417-26. doi:10.1083/jcb.200707043

76. Woolley CS, Gould E, Frankfurt M, McEwen BS. Naturally occurring fluctuation in dendritic spine density on adult hippocampal pyramidal neurons. J Neurosci (1990) 10:4035-9. doi:10.1523/JNEUROSCI.10-12-04035.1990

77. Woolley CS, McEwen BS. Estradiol mediates fluctuation in hippocampal synapse density during the estrous cycle in the adult rat. J Neurosci (1992) 12:2549-54. doi:10.1523/JNEUROSCI.12-07-02549.1992

78. Woolley CS, McEwen BS. Roles of estradiol and progesterone in regulation of hippocampal dendritic spine density during the estrous cycle in the rat. J Comp Neurol (1993) 336:293-306. doi:10.1002/cne.903360210

79. Kato A, Hojo Y, Higo S, Komatsuzaki Y, Murakami G, Yoshino H, et al. Female hippocampal estrogens have a significant correlation with cyclic fluctuation of hippocampal spines. Front Neural Circuits (2013) 7:149. doi:10.3389/fncir.2013.00149

80. Watanabe G, Taya K, Sasamoto S. Dynamics of ovarian inhibin secretion during the oestrous cycle of the rat. JEndocrinol (1990) 126:151-7. doi:10.1677/joe.0.1260151

81. Hojo Y, Okamoto M, Kato A, Higo S, Sakai F, Soya H, et al. Neurosteroid synthesis in adult female rat hippocampus, including androgens and allopregnanolone. J Steroids Hormon Sci (2014) S4:002. doi:10.4172/2157-7536.S4-002

82. Kimoto T, Ishii H, Higo S, Hojo Y, Kawato S. Semicomprehensive analysis of the postnatal age-related changes in the mRNA expression of sex steroidogenic enzymes and sex steroid receptors in the male rat hippocampus. Endocrinology (2010) 151:5795-806. doi:10.1210/en.2010-0581

83. Spencer JL, Waters EM, Milner TA, McEwen BS. Estrous cycle regulates activation of hippocampal Akt, LIM kinase, and neurotrophin receptors in C57BL/6 mice. Neuroscience (2008) 155:1106-19. doi:10.1016/j.neuroscience. 2008.05.049

84. Znamensky V, Akama KT, McEwen BS, Milner TA. Estrogen levels regulate the subcellular distribution of phosphorylated Akt in hippocampal CA1 dendrites. J Neurosci (2003) 23:2340-7.

85. Balthazart J, Ball GF. Is brain estradiol a hormone or a neurotransmitter? Trends Neurosci (2006) 29:241-9. doi:10.1016/j.tins.2006.03.004

86. Balthazart J, Baillien M, Ball GF. Phosphorylation processes mediate rapid changes of brain aromatase activity. J Steroid Biochem Mol Biol (2001) 79:261-77. doi:10.1016/S0960-0760(01)00143-1

87. Balthazart J, Baillien M, Ball GF. Interactions between kinases and phosphatases in the rapid control of brain aromatase. J Neuroendocrinol (2005) 17:553-9. doi:10.1111/j.1365-2826.2005.01344.x

88. Fester L, Brandt N, Windhorst S, Prols F, Blaute C, Rune GM. Control of aromatase in hippocampal neurons. J Steroid Biochem Mol Biol (2016) 160:9-14. doi:10.1016/j.jsbmb.2015.10.009

89. Munetsuna E, Hojo Y, Hattori M, Ishii H, Kawato S, Ishida A, et al. Retinoic acid stimulates 17beta-estradiol and testosterone synthesis in rat hippocampal slice cultures. Endocrinology (2009) 150:4260-9. doi:10.1210/ en.2008-1644

90. Fester L, Prange-Kiel J, Zhou L, Blittersdorf BV, Böhm J, Jarry H, et al. Estrogen-regulated synaptogenesis in the hippocampus: sexual dimorphism in vivo but not in vitro. J Steroid Biochem Mol Biol (2012) 131:24-9. doi:10.1016/j.jsbmb.2011.11.010

91. Prange-Kiel J, Schmutterer T, Fester L, Zhou L, Imholz P, Brandt N, et al. Endocrine regulation of estrogen synthesis in the hippocampus? Prog Histochem Cytochem (2013) 48:49-64. doi:10.1016/j.proghi.2013.07.002

92. Munetsuna E, Hattori M, Komatsu S, Sakimoto Y, Ishida A, Sakata S, et al. Social isolation stimulates hippocampal estradiol synthesis. Biochem Biophys Res Commun (2009) 379:480-4. doi:10.1016/j.bbrc.2008.12.076

93. Munetsuna E, Hattori M, Sakimoto Y, Ishida A, Sakata S, Hojo Y, et al. Environmental enrichment alters gene expression of steroidogenic enzymes in the rat hippocampus. Gen Comp Endocrinol (2011) 171:28-32. doi:10.1016/ j.ygcen.2010.12.007

94. Okamoto M, Hojo Y, Inoue K, Matsui T, Kawato S, McEwen BS, et al. Mild exercise increases dihydrotestosterone in hippocampus providing evidence for androgenic mediation of neurogenesis. Proc Natl Acad Sci U S A (2012) 109:13100-5. doi:10.1073/pnas.1210023109

95. Gage FH. Mammalian neural stem cells. Science (2000) 287:1433-8. doi:10.1126/science.287.5457.1433
96. Galea LA, Wainwright SR, Roes MM, Duarte-Guterman P, Chow C, Hamson DK. Sex, hormones and neurogenesis in the hippocampus: hormonal modulation of neurogenesis and potential functional implications. J Neuroendocrinol (2013) 25:1039-61. doi:10.1111/jne.12070

97. Hamson DK, Wainwright SR, Taylor JR, Jones BA, Watson NV, Galea LA. Androgens increase survival of adult-born neurons in the dentate gyrus by an androgen receptor-dependent mechanism in male rats. Endocrinology (2013) 154:3294-304. doi:10.1210/en.2013-1129

98. Pawluski JL, Brummelte S, Barha CK, Crozier TM, Galea LA. Effects of steroid hormones on neurogenesis in the hippocampus of the adult female rodent during the estrous cycle, pregnancy, lactation and aging. Front Neuroendocrinol (2009) 30:343-57. doi:10.1016/j.yfrne.2009.03.007

99. Spritzer MD, Galea LA. Testosterone and dihydrotestosterone, but not estradiol, enhance survival of new hippocampal neurons in adult male rats. Dev Neurobiol (2007) 67:1321-33. doi:10.1002/dneu.20457

100. Marlatt MW, Potter MC, Lucassen PJ, van Praag H. Running throughout middle-age improves memory function, hippocampal neurogenesis, and BDNF levels in female C57BL/6J mice. Dev Neurobiol (2012) 72:943-52. doi:10.1002/dneu.22009

101. van Praag H, Christie BR, Sejnowski TJ, Gage FH. Running enhances neurogenesis, learning, and long-term potentiation in mice. Proc Natl Acad Sci U S A (1999) 96:13427-31. doi:10.1073/pnas.96.23.13427

102. Grassi S, Tozzi A, Costa C, Tantucci M, Colcelli E, Scarduzio M, et al. Neural 17beta-estradiol facilitates long-term potentiation in the hippocampal CA1 region. Neuroscience (2011) 192:67-73. doi:10.1016/j.neuroscience.2011.06.078

103. Tanaka M, Sokabe M. Continuous de novo synthesis of neurosteroids is required for normal synaptic transmission and plasticity in the dentate gyrus of the rat hippocampus. Neuropharmacology (2012) 62:2373-87. doi:10.1016/j.neuropharm.2012.02.007

104. Tanaka M, Sokabe M. Bidirectional modulatory effect of 17beta-estradiol on NMDA receptors via ERalpha and ERbeta in the dentate gyrus of juvenile male rats. Neuropharmacology (2013) 75:262-73. doi:10.1016/j. neuropharm.2013.07.029

105. Di Mauro M, Tozzi A, Calabresi P, Pettorossi VE, Grassi S. Neo-synthesis of estrogenic or androgenic neurosteroids determine whether long-term potentiation or depression is induced in hippocampus of male rat. Front Cell Neurosci (2015) 9:376. doi:10.3389/fncel.2015.00376

106. Hojo Y, Munetomo A, Mukai H, Ikeda M, Sato R, Hatanaka Y, et al. Estradiol rapidly modulates spinogenesis in hippocampal dentate gyrus: involvement of kinase networks. Horm Behav (2015) 74:149-56. doi:10.1016/j.yhbeh.2015.06.008

107. Tuscher JJ, Szinte JS, Starrett JR, Krentzel AA, Fortress AM, RemageHealey L, et al. Inhibition of local estrogen synthesis in the hippocampus impairs hippocampal memory consolidation in ovariectomized female mice. Horm Behav (2016) 83:60-7. doi:10.1016/j.yhbeh.2016.05.001

108. Fan L, Zhao Z, Orr PT, Chambers CH, Lewis MC, Frick KM. Estradiolinduced object memory consolidation in middle-aged female mice requires dorsal hippocampal extracellular signal-regulated kinase and phosphatidylinositol 3-kinase activation. J Neurosci (2010) 30:4390-400. doi:10.1523/ JNEUROSCI.4333-09.2010

109. Fernandez SM, Lewis MC, Pechenino AS, Harburger LL, Orr PT, Gresack JE, et al. Estradiol-induced enhancement of object memory consolidation involves hippocampal extracellular signal-regulated kinase activation and membrane-bound estrogen receptors. JNeurosci (2008) 28:8660-7. doi:10.1523/JNEUROSCI.1968-08.2008

110. Murakami G, Hojo Y, Ogiue-Ikeda M, Mukai H, Chambon P, Nakajima K, et al. Estrogen receptor KO mice study on rapid modulation of spines and long-term depression in the hippocampus. Brain Res (2015) 1621:133-46. doi:10.1016/j.brainres.2014.12.002

Conflict of Interest Statement: The authors declare that the research was conducted in the absence of any commercial or financial relationships that could be construed as a potential conflict of interest.

Copyright (C) 2018 Hojo and Kawato. This is an open-access article distributed under the terms of the Creative Commons Attribution License (CC BY). The use, distribution or reproduction in other forums is permitted, provided the original author $(s)$ and the copyright owner are credited and that the original publication in this journal is cited, in accordance with accepted academic practice. No use, distribution or reproduction is permitted which does not comply with these terms. 